\title{
COMPLETE MOMENT CONVERGENCE FOR WEIGHTED SUMS OF EXTENDED NEGATIVELY DEPENDENT RANDOM VARIABLES
}

\author{
Meimei Ge And Xin DENG
}

Abstract. In this paper, some results on complete moment convergence for weighted sums of extended negatively dependent (END, for short) random variables are established. The results extend and improve the result of Baum and Katz (1965) from complete convergence for nonweighted sums of independent random variables to the case of weighted sums of END random variables under mild conditions.

Mathematics subject classification (2010): 60F15.

Keywords and phrases: Extended negatively dependent random variables, weighted sums, complete moment convergence.

\section{REFERENCES}

[1] L. E. BAUM, M. KATZ, Convergence rates in the law of large numbers, Transactions of the American Mathematical Society 120 (1) (1965), 108-123.

[2] Y. Chen, K. C. Yuen, K. W. NG, Precise large deviations of random sums in presence of negative dependence and consistent variation, Methodology and Computing in Applied Probability 13 (2011), 821-833.

[3] Y. S. Chow, Delayed sums and Borel summability of independent, identically distributed random variables, Bulletin of the Institute of Mathematics, Academia Sinica 1 (2) (1973), 207-220.

[4] Y. S. CHOw, On the rate of moment convergence of sample sums and extremes, Bulletin of the Institute of Mathematics, Academia Sinica 16 (3) (1988), 177-201.

[5] P. ERDôs, On a theorem of Hsu and Robbins, The Annals of Mathematical Statistics 20 (2) (1949), 286-291.

[6] M. L. GuO, D. J. ZHU, Equivalent conditions of complete moment convergence of weighted sums for $\rho^{*}$-mixing sequence of random variables, Statistics and Probability Letters 83 (2013), 13-20.

[7] A. Gut, Complete convergence for arrays, Periodica Mathematica Hungarica 25 (1) (1992), 51-75.

[8] P. L. Hsu, H. Robisns, Complete convergence and the law of large numbers, Proceedings of the National Academy of Sciences USA, 33 (1947), 25-31.

[9] T. Z. HU, Negatively superadditive dependence of random variables with applications, Chinese Journal of Applied Probability and Statistics 16 (2000), 133-144.

[10] K. JoAG-DeV, F. Proschan, Negative association of random variables with applications, The Annals of Statistics 11 (1) (1983), 286-295.

[11] M. L. KATZ, The probability in the tail of a distribution, The Annals of Mathematical Statistics 34 (1) (1963), 312-318.

[12] L. LiU, Precise large deviations for dependent random variables with heavy tails, Statistics Probability Letters 79 (2009), 1290-1298.

[13] L. LiU, Necessary and sufficient conditions for moderate deviations of dependent random variables with heavy tails, Science in China Series A: Mathematics 53 (2010), 1421-1434.

[14] A. T. SHEN, Probability inequalities for END sequence and their applications, Journal of Inequalities and Applications, Vol. 2011, Article ID 98, 12 Pages, 2011.

[15] A. T. SHEN, A. Volodin, Weak and strong laws of large numbers for arrays of rowwise END random variables and their applications, Metrika 80 (2017), 605-625. 
[16] A. T. Shen, M. X. XUE, A. Volodin, Complete moment convergence for arrays of rowwise NSD random variables, Stochastics: An International Journal of Probability and Stochastic Processes $\mathbf{8 8}$ (4) (2016), 606-621.

[17] A. T. SHEN, Y. ZHANG, W. J. WANG, Complete convergence and complete moment convergence for extended negatively dependent random variables, Filomat 31 (5) (2017), 1381-1394.

[18] S. H. Sung, Moment inequalities and complete moment convergence, Journal of Inequalities and Applications, Vol. 2009, Article ID 271265, 14 pages, 2009.

[19] S. H. Sung, Complete convergence for weighted sums of $\rho^{*}$-mixing random variables, Discrete Dynamics in Nature and Society, Vol. 2010, Article ID 630608, 13 pages, 2010.

[20] S. J. WANG, X. J. WANG, Precise large deviations for random sums of END real-valued random variables with consistent variation, Journal of Mathematical Analysis and Applications 402 (2013), 660-667.

[21] X. J. WANG, S. H. Hu, Complete convergence and complete moment convergence for martingale difference sequence, Acta Mathematica Sinica, English Series 30 (2014), 119-132.

[22] X. J. Wang, S. J. Wang, S. H. HU, J. M. Ling, On Complete convergence of weighted sums for arrays of rowwise extended negatively dependent random variables, Stochastics: An International Journal of Probability and Stochastics Processes 85 (2013), 1060-1072.

[23] X. J. Wang, L. L. Zheng, C. XU, S. H. Hu, Complete consistency for the estimator of nonparametric regression models based on extended negatively dependent errors, Statistics: A Journal of Theoretical and Applied Statistics 49 (2015), 396-407.

[24] Y. WU, X. J. WANG, S. H. HU, Complete moment convergence for weighted sums of weakly dependent random variables and its application in nonparametric regression model, Statistical and Probability Letters 127 (2017), 56-66.

[25] Y. F. WU, M. O. CABREA, A. Volodin, Complete convergence and complete moment convergence for arrays of rowwise END random variables, Glasnik Matematički 49 (69) (2014), 449-468.

[26] Y. F. WU, J. Y. PENG, T. C. HU, Limiting behaviour for arrays of row-wise END random variables under conditions of h-integrability, Stochastics: An International Journal of Probability and Stochastics Processes 87 (3) (2015), 409-423.

[27] W. Z. YANG, H. Y. XU, L. Chen, S. H. Hu, Complete consistency of estimators for regression models based on extended negatively dependent errors, Statistical papers, 2018, 59 (2) (2017), 449465 . 